\title{
Neighborhood social disorganization and the acquisition of trichomoniasis among young adults in the United States
}

\author{
Jodi L. Ford, Ph.D. and \\ Ohio State University College of Nursing 320 Newton Hall/1585 Neil Ave. Columbus, OH 43210 \\ 614-292-6862 (phone) 614-292-4948 (fax) ford.553@osu.edu \\ Christopher R. Browning, Ph.D. \\ Ohio State University Department of Sociology 214 Townshend Hall/1885 Neil Ave Mall \\ Columbus, OH 43210 614-292-2983 (phone) browning.90@osu.edu
}

\begin{abstract}
Objective-To examine relationships between neighborhood social disorganization and trichomoniasis among young adults in the U.S.
\end{abstract}

\begin{abstract}
Methods-Multilevel logistic regression modeling was employed using secondary data from Wave III of the National Longitudinal Study of Adolescent Health (2001-2002). The dependent variable -trichomoniasis was measured via urine testing. Neighborhood social disorganization was measured via 4 indicators from the 2000 U.S. Census: racial and ethnic composition, concentrated poverty and residential instability. The sample was comprised of 11,370 individuals across 4,912 neighborhoods.
\end{abstract}

Results-Trichomoniasis was more likely to occur in neighborhoods with higher concentrations of Black residents $(\mathrm{AOR}=1.16,95 \% \mathrm{CI}=1.03,1.30)$. However, this association was mediated by neighborhood concentrated poverty. Furthermore, young adults who lived in neighborhoods with higher concentrations of poverty were significantly more likely to have trichomoniasis $(\mathrm{AOR}=1.25,95 \% \mathrm{CI}=1.07,1.46)$. Neither immigrant concentration nor residential instability was significantly associated with trichomoniasis.

Conclusions-These findings strengthen the evidence that neighborhood structural conditions are associated with individual STI acquisition. Research is needed to explore the mechanisms through which these conditions influence STI. In addition, STI prevention programs that include structural interventions targeting neighborhood disadvantage are needed.

Adolescents and young adults are at increased risk for sexually transmitted infections (STIs) due to a complex interplay of biological, behavioral and developmental factors. ${ }^{1}$ Nearly half of all STIs diagnosed in the U.S. annually are among adolescents and young adults ${ }^{1,2}$ despite national priority goals aimed at reducing infection rates. ${ }^{3}$ Trichomoniasis, a common and easily curable STI, ${ }^{1}$ is of increasing concern because the infection facilitates HIV acquisition and transmission through mucosal inflammation of the genital tract and alterations in the innate immune response. ${ }^{4-7}$ The infection is caused by the protozoa, Trichomonas vaginalis and is typically transmitted via penis-to-vagina or vulva-to-vulva contact. ${ }^{1}$ Infected persons are often asymptomatic or experience only mild symptoms, ${ }^{1}$ which can hinder early detection and treatment and increase the risk for STI/HIV.

In the U.S., the prevalence of trichomoniasis is difficult to ascertain because routine screening currently is not recommended nor is the reporting of positive infections 
required. ${ }^{1,4}$ According to urine assay data from the National Longitudinal Study of Adolescent Health (Add Health), the prevalence of trichomoniasis among the young adult male and female population in 2001-2002 was approximately $2.3 \% .^{7}$ The study also found women were at greater risk than men (2.8\% vs. $1.7 \%)$ as were non-Hispanic Black (6.9\%) and Latino $(2.1 \%)$ youth compared to their non-Hispanic White peers $(1.2 \%){ }^{7}$ In other studies of adult women, individual risk factors for trichomoniasis included poverty, lower education, douching, non-Hispanic Black race/ethnicity and greater numbers of lifetime sexual partners. ${ }^{8,9}$ Among clinic samples of adolescent women, research found trichomoniasis to be associated with older male sex partners, casual sex, marijuana use and delinquency. ${ }^{10}$

However, to date, no studies have examined the role of the broader structural context in shaping trichomoniasis risk, despite theory and previous STI research suggesting the neighborhood environment may play a role. According to social disorganization theory, ${ }^{11-14}$ key indicators of neighborhood structural disadvantage - racial/ethnic composition, concentrated poverty, and residential instability influence health outcomes by weakening social ties, reducing access to institutional resources, and limiting exposure to positive role models, conventional social norms and collective efficacy. Findings from prior research examining other STIs are supportive of the hypothesis that neighborhood contexts influence STI prevalence. For example, with respect to racial and ethnic composition, studies have found that gonorrhea rates were higher in cities and neighborhoods with greater proportions of Black residents. ${ }^{15,16}$ Furthermore, in an analysis of Chicago neighborhoods, the incidence rates of gonorrhea and Chlamydia were higher in neighborhoods where greater than $60 \%$ of the residents were Black compared to those where greater than $60 \%$ of residents were Hispanic, which suggests that segregated Hispanic ethnic enclaves may be protective of STI compared to segregated Black communities. ${ }^{17}$ Researchers hypothesize residential segregation of Black communities increases STI risk because of historical and persistent discrimination, which in turn has contributed to greater concentration of poverty, lower male: female sex ratios due to the disproportionate incarceration of Black males and greater assortative sexual mixing patterns compared to other racial and ethnic groups leading to closed sexual networks and increased STI transmission. ${ }^{18-20}$

In addition, the role of community poverty in shaping STI has been examined extensively and found to be positively associated with rates of Chlamydia, gonorrhea, syphilis and HIV in cross-sectional ${ }^{15,17,21-23}$ and longitudinal analyses. ${ }^{16}$ Other socioeconomic factors, such as unemployment ${ }^{17,24}$ and lower educational attainment ${ }^{16,17}$ also have been linked to higher rates of Chlamydia and gonorrhea. Research on the effects of residential instability on STI is limited, but the one study that examined these relationships found greater residential instability was associated with fewer self-reported STIs among a national sample of adolescents. ${ }^{24}$ Depending on the context, perhaps residential instability could increase STI risk by disrupting social support ties and informal social control measures or reduce STI risk by dispersing closed sexual networks that facilitate infection transmission.

Although the aforementioned studies have illustrated links between neighborhood social disorganization and a variety of STIs, limitations exist. First, the majority are ecological studies, in which the outcomes are measured as community STI rates and no adjustment is made for potential confounding relationships with individual-level data. ${ }^{15-17,21-23}$

Consequently, inferences can be made only about the community, and individual variation in the outcome cannot be ascertained. ${ }^{25}$ Second, although one study examined individual STI, the measure was based on self-report ${ }^{24}$, which potentially increases bias due to underreporting as well as unrecognized and/or undiagnosed infection. In addition, the study only focused on STI in general, which could limit our understanding of unique relationships with specific infectious organisms. Third, data sources of previous research tend to be at local or 
state levels, ${ }^{15-17,21-23}$ which limits external validity of the findings. Therefore, the purpose of our research was to examine relationships between neighborhood social disorganization and trichomoniasis among young adults in the U.S. Our research builds on prior studies in three significant ways: (1) we examined multiple levels of analysis, which enabled us to simultaneously examine the independent relationships between individual and neighborhood variables and individual acquisition of trichomoniasis, (2) we examined a more refined measure of STI through the use of urine screening and (3) we examined data from a large national data set -Add Health.

\section{METHODS}

\section{Study Design and Sample}

We used cross-sectional data from Add Health, Wave III (2001-2002) ${ }^{26}$ to examine associations between current neighborhood conditions and trichomoniasis. Add Health is a school-based, longitudinal study of students in 7th-12th grade that utilized a multistage, stratified and clustered sampling design to ensure a nationally representative sample of U.S. schools with respect to region of country, urbanicity, school size, school type and ethnicity. ${ }^{27}$ Four waves of data have been collected spanning from adolescence to young adulthood. Data are available from multiple sources, including adolescents, parents, partners, schools and communities. Wave III individual data were collected in 2001-2002 and the neighborhood data were derived from the 2000 U.S. Census. Wave III of Add Health is comprised of those respondents from Wave I who were able to be relocated and interviewed during the data collection time frame $(\mathrm{N}=15,170)$. The response rate for Wave III was $77.4 \% .{ }^{27}$ Add Health provides sampling weights to adjust for non-response at Waves I and III ${ }^{27}$ and when utilized, the two samples are comparable. ${ }^{28} \mathrm{~A}$ total of 14,322 young adults from Wave III have sampling weights and of these, 12,446 respondents had urine assay results for trichomoniasis. Participants missing data on independent variables were excluded from analysis $(n=1,076)$. Thus, the final sample size for this study included 11,370 individuals across 4,912 neighborhoods. The young adults who were excluded due to missing data on trichomoniasis or the independent variables $(\mathrm{N}=2,644)$ were more likely than those included $(\mathrm{N}=11,370)$ to be male, living with their parents, minority race or ethnicity, and have no history of vaginal sex. In addition, they were less likely to be low income, married, employed, in school and to report using drugs. No significant difference was found in the odds of trichomoniasis between the final sample and those who were excluded due to missing data on the independent variables $(\mathrm{N}=1,076)$.

\section{Dependent Variables}

The dependent variable - trichomoniasis was measured via urine assay screening, thus results were binary in nature with positive urine screens coded "1". Add Health researchers collected respondents' first stream urine on the day of interview. The urine was then tested for trichomoniasis via PCR-ELISA. ${ }^{29,30}$ Urine testing to detect the STI is still considered experimental, but the measure has been validated with wet mount and culture in published studies. ${ }^{29,30}$

\section{Independent Variables}

Individual-level variables-Individual-level variables were based on respondent self report and selected for inclusion based on previous research and theory. Sociodemographic characteristics included age (continuous measure), gender $($ male $=1$ ), married (yes $=1$ ), race and ethnicity (non-Hispanic White, non-Hispanic Black, non-Hispanic American Indian, non-Hispanic Asian and Hispanic), foreign birth (yes=1), economic hardship (if received food stamps, housing assistance or AFDC in the past year coded yes=1), employed at least 10 hours weekly (yes=1), enrolled in high school or college (yes=1), current residence in 
parental household (yes $=1$ ), individual residential stability (continuous variable of the number of years resided in current neighborhood) and heterosexual orientation (yes=1). In addition, antibiotic use in past month (yes=1) was included to adjust for possible treatment of an undiagnosed STI prior to urine screening. STI-risk factors included sexual risk behaviors and substance use. Sexual risk behavior controls included a continuous measure of the number of sexual partners in the past year, and categorical measures of age at first vaginal intercourse (never had sex=reference vs. aged 10-15 years, 16-17 years and 18 years or greater), exchanged money for sex in past year (yes=1), and had sex with an IV drug user in past year (yes=1). Substance use measures included level of binge drinking in past year (continuous measure of the number of days during the past year the respondent drank five or more drinks ranging from never to every/almost every day) and a categorical measure of drug use in the past year (yes $=1$ if respondent used marijuana, cocaine, methamphetamine, or other illegal drugs).

Neighborhood-level variables-The neighborhood was defined as a geographic unit and measured as the census tract of residence. Census tracts commonly serve as proxies for neighborhoods and are often the basis for geographically delimited resource allocation. 31,32 Neighborhood social disorganization was measured via 4 indicators based on theory, ${ }^{11-14}$ previous research ${ }^{33-35}$ and available data: racial and ethnic composition, concentrated poverty and residential instability. Racial and ethnic composition was measured via 2 variables - (1) non-Hispanic Black concentration, which was composed of one standardized item: proportion of Black residents living in the census tract and (2) immigrant concentration, which was composed of 3 standardized items: proportion of Latino/Hispanic residents, proportion of linguistically isolated residents and proportion of foreign born residents. Exploratory factor analysis and internal consistency was conducted and results supported the inclusion of the 3 immigrant concentration items into one index (factor loadings $>0.65$ onto one factor and internal consistency $a=.95$ ).

Concentrated poverty was a composite of 4 standardized items: proportion of households below poverty, proportion of households on public assistance, total unemployment rate and proportion of female-headed households with children. Exploratory factor analysis and internal consistency was conducted and results supported the inclusion of the 4 items into one index (factor loadings $>0.65$ onto one factor and internal consistency $a=.82$ ).

Residential instability was composed of 2 standardized items: proportion of households living in the census tract for 5 years or more and proportion of owner occupied homes. Internal consistency was $a=.82$. Last, two neighborhood control variables were included: region (Northeast, Midwest, West and South-reference) and urbanicity (standardized item of proportion of persons living in an urbanized area).

\section{Analysis}

Descriptive analyses were conducted using SAS software, version 9.2 (SAS Institute, Cary, NC) to better understand the characteristics and prevalence of trichomoniasis among our sample. Multilevel logistic regression modeling using HLM software, version 6.08 (Scientific Software International, Lincolnwood, IL) was subsequently conducted to examine the contribution of neighborhood social disorganization to trichomoniasis among young adults, adjusting for individual and neighborhood control variables. Because the prevalence of trichomoniasis in the sample was low (2\%), odds-ratios approximate relative risk ratios. ${ }^{36}$ However, we also analyzed the data using the Poisson distribution and findings were consistent with those from the logistic regression analyses presented in this paper. We examined a series of 3 random intercept models based on the theory that concentrated poverty and residential instability may mediate relationships between racial and ethnic composition and trichomoniasis. Consequently, model 1 included individual and 
neighborhood-level control variables and the two variables measuring racial and ethnic composition. In models 2 and 3, we included the variables, concentrated poverty and residential instability into the analyses respectively. Continuous variables were grand mean centered. Multicollinearity was examined prior to multilevel analyses; tolerance and variance inflation factors were within range. The findings presented are from unweighted analyses because Add Health sampling weights account only for the clustering of schools and not neighborhoods. Thus, their inclusion could lead to erroneous findings (personal communication, Kim Chantala, Add Health User's Conference, 2008). However, we conducted sensitivity analyses using the weights and found no differences in statistical significance, although the strength of the associations was greater for weighted versus unweighted analyses.

\section{RESULTS}

Descriptive statistics for the sample are presented in Table 1, including unweighted and weighted proportions and means. The unweighted and weighted findings were in accordance with each other except for race and ethnicity due to oversampling and weighted adjustments. Unweighted findings indicate the prevalence of trichomoniasis was $2.4 \%$ among the sample. Approximately $47 \%$ of the sample was male and the mean age was 22 years. Approximately 56\% self-identified as White, 20\% Black, 16\% Hispanic, 7\% Asian and 1\% American Indian and $8 \%$ were foreign born. In respect to socioeconomic position, $7 \%$ reported economic hardship in the past year, 70\% were employed at least part time and 38\% were enrolled in high school or college. In addition, $18 \%$ of the young adults were married, $89 \%$ reported heterosexual orientation and $40 \%$ lived with their parents. Respondents lived an average of 5.7 years at their current residence. The majority (88\%) reported a history of vaginal intercourse and the average number of vaginal sexual partners in the previous year was 1.5 . Nearly $34 \%$ reported illicit drug use in the past year and the mean binge drinking score was 1.2 or approximately 1-2 binge drinking episodes in the past year.

Findings from unweighted multivariate analyses on the associations between neighborhood social disorganization and trichomoniasis are presented in Table 2. In model 1, we examined associations between neighborhood racial and ethnic composition and trichomoniasis and found young adults who lived in neighborhoods with higher proportions of Black residents were more likely to have trichomoniasis, after adjusting for individual and neighborhoodlevel control variables $(\mathrm{AOR}=1.16,95 \% \mathrm{CI}=1.03,1.30)$. No significant association was found between immigrant concentration and trichomoniasis. In model 2, we introduced concentrated poverty into the regression equation and found young adults who lived in neighborhoods with higher proportions of concentrated poverty had significantly higher odds of having trichomoniasis ( $\mathrm{AOR}=1.19,95 \% \mathrm{CI}=1.02,1.38$ ). In addition, consistent with our hypothesis, concentrated poverty mediated the relationship between neighborhood concentration of Black residents and trichomoniasis ( $\mathrm{AOR}=1.05,95 \% \mathrm{CI}=0.91,1.21)$. These findings suggest the neighborhood racial disparity in trichomoniasis was attributed to a greater concentration of poverty in these neighborhoods. Last, residential instability was entered into the regression equation in model 3 , but no significant associations with trichomoniasis were found $(\mathrm{AOR}=0.87,95 \% \mathrm{CI}=0.73,1.04)$. However, concentrated poverty remained statistically significant; for every unit increase in concentrated poverty, the odds of infection increased by $25 \%$ ( $\mathrm{AOR}=1.25,95 \% \mathrm{CI}=1.07,1.46)$.

Several significant individual-level associations also were found (see Model 3). Specifically, in relation to STI disparities, males were less likely to have trichomoniasis than females $(\mathrm{AOR}=0.65,95 \% \mathrm{CI}=0.49,0.87)$. Non-Hispanic Black $(\mathrm{AOR}=3.54,95 \% \mathrm{CI}=2.47,5.08)$ and Hispanic youth $(\mathrm{AOR}=1.75,95 \% \mathrm{CI}=1.07,2.84)$ had approximately 3.5 and 1.7 times the odds of trichomoniasis, respectively, when compared with non-Hispanic White youth. 
Socioeconomic disparities also were found as young adults who reported economic hardship were more likely to have trichomoniasis ( $\mathrm{AOR}=1.65,95 \% \mathrm{CI}=1.18,2.31$ ) compared to their more socioeconomically advantaged peers. Being enrolled in school (AOR $=0.67,95 \%$ $\mathrm{CI}=0.50,0.91$ ) or being employed $(\mathrm{AOR}=0.67,95 \% \mathrm{CI}=0.53,0.86$ ) were each independently protective against the STI. None of the STI risk factors were significantly associated with trichomoniasis.

\section{DISCUSSION}

Our study found that key indicators of neighborhood social disorganization were significantly related to the acquisition of trichomoniasis among a sample of young adults, above and beyond individual and neighborhood control variables. Specifically, we found young adults who lived in neighborhoods with a higher concentration of Black residents were more likely to have trichomoniasis compared to those who lived in neighborhoods with lower concentrations of Black residents. However, concentrated poverty mediated this relationship, and once adjusted, the relationship between neighborhood concentration of Black residents and trichomoniasis was not significant. These findings suggest that the neighborhood racial disparity in young adults' acquisition of trichomoniasis is due to higher levels of concentrated poverty within segregated Black neighborhoods. Our findings are consistent with theory on the pathways through which racial residential segregation contributes to STI outcomes. ${ }^{18-20}$ However, prior ecological analyses found that even after adjusting for community-levels of poverty, gonorrhea rates were significantly higher in communities with greater concentrations of Black residents. ${ }^{15,16}$ Although not shown, we found similar results, but the association between neighborhood concentration of Black residents and trichomoniasis was not statistically significant once individual-level factors were introduced into the model. Consequently, the disparate findings between our study and prior research may be due to our use of multilevel modeling, which enables adjustment of individual-level factors that may potentially mediate or confound relationships between neighborhoods and individual outcomes. ${ }^{25}$

Consistent with prior research, ${ }^{15-17,21-23}$ we found significant associations between neighborhood concentrated poverty and young adults' acquisition of trichomoniasis. These findings illustrate the deleterious relationships between neighborhood poverty and trichomoniasis among young adults and future research is needed to investigate the pathways through which neighborhood poverty shapes STI outcomes, including racial, ethnic and socioeconomic disparities. For example, previous studies support the role of social processes, such as social cohesion, collective efficacy and high-risk behavioral norms in mediating and/or moderating relationships between neighborhood structural conditions and sexual risk behavior ${ }^{33-35,38}$ as well as community STI rates. ${ }^{37}$ Thus, future studies should explore these potential explanations. In addition, researchers should consider the mediating and/or moderating role of neighborhood sexual network structure as neighborhood social disorganization may contribute to more closed and assortative sexual networks that increase STI risk compared to more advantaged neighborhoods ${ }^{39}$ Last, physical disorder also may play a role as previous ecological research found that gonorrhea rates were higher in neighborhoods characterized by boarded-up housing, graffiti, accumulating garbage, abandoned vehicles and poor physical conditions of public high schools. ${ }^{21}$ Furthermore, the association was independent of neighborhood poverty. The findings support Wilson and Kelling's "broken windows" hypothesis that neighborhood physical disorder may signal neglect, diminished social control and greater tolerance for high-risk behavior to neighborhood residents and outsiders. ${ }^{40}$ Future multilevel research should explore these potential relationships with a variety of STI organisms. 
In contrast to theory ${ }^{11-14}$ and previous research, ${ }^{24}$ neither immigrant concentration nor residential instability was associated with the acquisition of trichomoniasis in our study. First, with respect to immigrant concentration, the majority of our sample lived in neighborhoods that contained few immigrant residents. This limitation may have reduced the power to detect significant relationships that may occur in more segregated neighborhoods. Second, residential instability was found to be negatively associated with adolescent self-reported STI in a previous study that also used Add Health data. ${ }^{24}$

Methodological differences between our studies as well as developmental differences in our samples may account for the disparate findings. Specifically, our study utilized multilevel analyses, urine assay data of a specific STI and neighborhood data collected in 2000 while prior research employed contextual analyses, self-report of STI and neighborhood data collected in 1990. Developmentally, young adults also may be more likely to live in neighborhoods with greater residential mobility, such as college campuses and apartment communities. This developmental transition is normative, thus residentially unstable environments may have less of an impact. Future research on the role of residential instability on health outcomes over the life course is needed to elicit potential developmental differences.

In addition to our neighborhood findings, we also found disparities at the individual-level for gender, race/ethnicity and socioeconomic position. These findings are consistent with previous research and are hypothesized to be attributed to a complex interplay of individual, sexual network, community, institutional and policy-related factors. ${ }^{1,2,7-10}$ Future research should examine these potential mediators and also explore the extent to which relationships between neighborhood social disorganization and STI are moderated by individual sociodemographic factors as neighborhoods may influence the acquisition and transmission of STI differently for individuals with different levels of risk. In contrast to previous research ${ }^{8-10}$ STI risk behaviors were not statistically associated with trichomoniasis in our study. In bivariate analysis (not shown), we did find that trichomoniasis was significantly associated with a greater likelihood of exchanging sex for money, younger age at first intercourse (vs. no sexual intercourse) and binge drinking, but these relationships were not statistically significant when sociodemographic variables were included in multivariate analyses. These disparate findings may be due to measurement error or potentially to differences in the pathogenesis of specific STIs.

Several limitations to our study warrant further discussion. First, this study is crosssectional, thus causal inferences cannot be made. Second, Add Health questions related to anal sex are asked only in a section on detailed relationships. However, 1,852 young adults in our sample did not complete this section $(2.8 \%$ of these tested positive for trichomoniasis). Consequently, we were unable to adjust for anal sex as a risk factor and used sexual orientation as a crude proxy. The prevalence of trichomoniasis for those who did not complete the relationship data file was consistent with the overall sample, which suggests the trichomoniasis risk for those with relationship data and those missing may be similar. Additionally, because trichomoniasis is not typically transmitted via anal sex ${ }^{1}$, bias from the omitted variable may be minimal. Third, Add Health's school-based design limited the sample to young adults attending school at Wave 1 (1995). Thus, the sample does not include high-risk youth in the community at Wave 1 who dropped out of school. The Wave 3 sample does include young adults who participated in Wave 1, but dropped out of school after their Wave 1 interview. Last, Wave III Add Health data do not contain STI prevalence information at any geographic level, thus we could not capture infectious disease risk at the community-level.

Despite these limitations, our study offers evidence that neighborhood poverty is associated with young adults' acquisition of trichomoniasis, above and beyond known individual risk 
and protective factors. Furthermore, we found that the neighborhood racial disparity in trichomoniasis was attributed to higher concentrations of poverty in these areas. The Centers for Disease Control and Prevention's (CDC) Strategic Plan for 2008-2013 calls for a reduction in STI disparities and enhanced efforts to address the social and economic determinants of STI, including the incorporation of structural interventions into their STI prevention efforts. ${ }^{41}$ Consequently, further research is needed to better understand the pathways through which neighborhood poverty contributes to STI and STI disparities, including studies on how to effectively create structural change aimed at eliminating neighborhood poverty.

\section{Acknowledgments}

The authors received Seed Grant support for this research from the Initiative in Population Research at The Ohio State University, which is funded by National Institutes of Health, Eunice Kennedy Shriver National Institute of Child Health \& Human Development (R24HD058484). In addition, this research used data from Add Health, a program project directed by Kathleen Mullan Harris, designed by J. Richard Udry, Peter S. Bearman, and Kathleen Mullan Harris at the University of North Carolina at Chapel Hill, and funded by the Eunice Kennedy Shriver National Institute of Child Health and Human Development (grant P01-HD31921), with cooperative funding from 23 other federal agencies and foundations. No direct support was received from grant P01-HD31921 for this analysis. Special acknowledgment is due Ronald R. Rindfuss and Barbara Entwisle for assistance in the original design. Information on how to obtain the Add Health data files is available on the Add Health Web site (available at: http://www.cpc.unc.edu/addhealth). Last, we thank our reviewers and editors for their time and suggestions.

\section{REFERENCES}

1. Centers for Disease Control and Prevention. [July 25, 2010] Sexually Transmitted Diseases Surveillance. 2008. Available at: http://www.cdc.gov/std/stats08/main.htm

2. Weinstock H, Berman S, Cates W. Sexually transmitted diseases among American youth: Incidence and prevalence estimates, 2000. Perspect Sex Reprod Health. 2004; 36:6-10. [PubMed: 14982671]

3. Healthy People 2010. [January 5, 2010] Sexually transmitted infections: Midcourse review. 2006. Available at: http://www.healthypeople.gov/Data/midcourse/html/focusareas/FA25References.htm

4. Thurman AR, Doncel GF. Innate immunity and inflammatory response to Trichomonas vaginalis: relationship to HIV acquisition. Am J Reprod Immunol. 2010 e-pub ahead of print.

5. Laga M, Manoka A, Kivuvu M, Malele B, Tuliza M, Nzila N, Goeman J, Behets F, Batter V, Alary M. Non-ulcerative sexually transmitted diseases as risk factors for HIV-1 transmission in women: results from a cohort study. AIDS. 1993; 7:95-102. [PubMed: 8442924]

6. McClelland RS, Sangare L, Hassan WM, Lavreys L, Mandaliya K, Kiarie J, Nfinya-Achola J, Jaoko W, Baeten JM. Infection with Trichimonas vaginalis increases the risk of HIV-1 acquisition. J Infect Dis. 2007; 195:698-702. [PubMed: 17262712]

7. Miller WC, Swygard H, Hobbs MM, Ford CA, Handcock MS, Morris M, Schmitz JL, Cohen MS, Harris KM, Udry JR. The prevalence of trichomoniasis in young adults in the United States. Sex Transm Dis. 2005; 32:593-8. [PubMed: 16205299]

8. Sutton M, Sternberg M, Koumans EH, McQuillan G, Berman S, Markowitz L. The prevalence of Trichomonas vaginalis infection among reproductive-age women in the United States, 2001-2004. Clin Infect Dis. 2007; 45:1319-26. [PubMed: 17968828]

9. Allsworth JE, Ratner JA, Peipert JF. Trichomoniasis and other sexually transmitted infections: results from the 2001-2004 National Health and Nutrition Examination Surveys. Sex Transm Dis. 2009; 36:738-44. [PubMed: 19734826]

10. Krashin JW, Koumans EH, Bradshaw-Sydnor AC, Braxton JR, Evan Secor W, Sawyer MK, Markowitz LE. Trichomonas vaginalis prevalence, incidence, risk factors and antibiotic-resistance in an adolescent population. Sex Transm Dis. Jul; 2010 37(7):440-4. [PubMed: 20351623]

11. Shaw, CR.; McKay, HD. Juvenile Delinquency and Urban Areas. The University of Chicago Press; Chicago: 1969.

12. Sampson RJ, Raudenbush S, Earls F. Neighborhoods and violent crime: A multilevel study of collective efficacy. Science. 1997; 277:918-24. [PubMed: 9252316] 
13. Wilson, WJ. The Truly Disadvantaged: The Inner City, the Underclass, and Public Policy. University of Chicago Press; Chicago: 1987.

14. Jencks, C.; Mayer, SE. The social consequences of growing up in a poor neighborhood.. In: Lynn, LE.; McGeary, MGH., editors. Inner-City Poverty in the United States. National Academy of Press; Washington, DC: 1990. p. 111-186.

15. Cohen DA, Mason K, Bedimo A, Scribner R, Basolo V, Farley TA. Neighborhood physical conditions. Am J Public Health. 2003; 93:467-471. [PubMed: 12604497]

16. Du P, McNutt LA, O'Campo P, Coles FB. Changes in community socioeconomic status and racial distribution associated with gonorrhea rates: an analysis at the community level. Sex Transm Dis. 2009; 36:430-8. [PubMed: 19556936]

17. Kaplan MS, Crespo CJ, Huguet N, Marks G. Ethnic/racial homogeneity and sexually transmitted disease: a study of 77 Chicago community areas. Sex Transm Dis. Feb; 2009 36(2):108-11. [PubMed: 19125143]

18. Laumann EO, Youm Y. Racial/ethnic group differences in the prevalence of sexually transmitted diseases in the United States: a network explanation. Sex Transm Dis. 1999; 26:250-61. [PubMed: 10333277]

19. Adimora AA, Schoenbach VJ. Social context, sexual networks, and racial disparities in rates of sexually transmitted infections. J Infect Dis. 2005; 191(Suppl 1):S115-22. [PubMed: 15627221]

20. Khan MR, Doherty IA, Schoenbach VJ, Taylor EM, Epperson MW, Adimora AA. Incarceration and high-risk sex partnerships among men in the United States. J Urban Health. 2009; 86:584601. [PubMed: 19459050]

21. Cohen D, Spear S, Scribner R, Kissinger P, Mason K, Wildgen J. "Broken Windows" and the risk of gonorrhea. Am J Public Health. 2000; 90:230-236. [PubMed: 10667184]

22. Krieger N, Waterman PD, Chen JT, Soobader MJ, Subramanian SV. Monitoring socioeconomic inequalities in sexually transmitted infections, tuberculosis, and violence: Geocoding and choice of area-based socioeconomic measures--The Public Health Disparities Geocoding Project (US). Public Health Rep. 2003; 118:240-260. [PubMed: 12766219]

23. Zierler S, Krieger N, Tang Y, et al. Economic deprivation and AIDS incidence in Massachusetts. Am J Public Health. 2000; 90:1064-1073. [PubMed: 10897184]

24. Upchurch D, Mason W, Kusonoki Y, Kriechbaum M. Social and behavioral determinants of selfreported STD among adolescents. Perspect Sex Reprod Health. 2004; 36:276-87. [PubMed: 15687086]

25. Diez Roux AV, Mair C. Neighborhoods and health. Ann N Y Acad Sci. Feb.2010 1186:125-45. [PubMed: 20201871]

26. Harris, KM. The National Longitudinal Study of Adolescent Health (Add Health), Waves I \& II, 1994-1996; Wave III, 2001-2002; Wave IV, 2007-2009 [machine-readable data file and documentation]. Carolina Population Center, University of North Carolina at Chapel Hill; Chapel Hill, NC: 2009.

27. Harris, KM.; Halpern, CT.; Whitsel, E.; Hussey, J.; Tabor, J.; Entzel, P.; Udry, JR. [July 25, 2010] The National Longitudinal Study of Adolescent Health: Research Design.. 2009. http:// www.cpc.unc.edu/projects/addhealth/design.

28. Chantala, K.; Kalsbeek, WD.; Andraca, E. [July 25, 2010] Non-Response in Wave III of the Add Health Study.. http://www.cpc.unc.edu/projects/addhealth/data/guides/W3nonres.pdf.

29. Ford, CA.; Florey, FA.; Tabor, J. [July 25, 2010] Chapter 3: STI and HIV testing: Field, transportation and notification procedures.. Biomarkers Wave III of the Add Health Study. http:// www.cpc.unc.edu/projects/addhealth/data/using/guides/biomark.pdf.

30. Hobbs, MM. [July 25, 2010] Trichomonas vaginalis testing.. Biomarkers Wave III of the Add Health Study. http://www.cpc.unc.edu/projects/addhealth/data/using/guides/biomark.pdf.

31. Leventhal T, Brooks-Gunn J. The neighborhoods they live in: The effects of neighborhood residence on child and adolescent outcomes. Psychol Bull. 2000; 126:309-337. [PubMed: 10748645]

32. Subramanian SV, Chen JT, Rehkopf DH, Waterman PD, Krieger N. Racial disparities in context: a multilevel analysis of neighborhood variations in poverty and excess mortality among black populations in Massachusetts. Am J Public Health. 2005; 95:260-265. [PubMed: 15671462] 
33. Browning CR, Burrington LA, Leventhal T, Brooks-Gunn J. Neighborhood structural inequality, collective efficacy, and sexual risk behavior among urban youth. J Health Soc Behav. 2008; 49:269-85. [PubMed: 18771063]

34. Browning CR, Leventhal T, Brooks-Gunn J. Neighborhood context and racial differences in early adolescent sexual activity. Demography. 2004; 41:697-720. [PubMed: 15622950]

35. Browning CR, Olinger-Wilbon M. Neighborhood structural disadvantage, social organization, and number of short-term sexual partnerships.". J Marriage Fam. 2003; 65:730-45.

36. Hosmer, DW.; Lemeshow, S. Applied Logistic Regression. John Wiley \& Sons; NY, New York: 2000.

37. Thomas JC, Torrone EA, Browning CR. Neighborhood factors affecting rates of sexually transmitted diseases in Chicago. J Urban Health. 2009; 87:102-112. [PubMed: 19997865]

38. Kerrigan D, Witt S, Glass B, Chung SE, Ellen J. Perceived neighborhood social cohesion and condom use among adolescents vulnerable to HIV/STI. AIDS Behav. 2006; 10:723-9. [PubMed: 16845598]

39. Fichtenberg CM, Jennings JM, Glass TA, Ellen JM. Neighborhood socioeconomic environment and sexual network position. J Urban Health. Mar; 2010 87(2):225-35. [PubMed: 20140533]

40. Wilson JQ, Kelling G. Broken windows: The police and neighborhood safety. Atlantic Monthly. 1982; 3:29-38.

41. Centers for Disease Control and Prevention. [July 12, 2010] Division of STD prevention strategic plan 2008-2013.. www.cdc.gov/STD/general/DSTDP-Strategic-Plan-2008.pdf. 
Table 1

Characteristics of the sample of young adults aged 18-27 years, 2001-2002 National Survey of Adolescent Health (Add Health), $\mathrm{N}=11,370$ young adults across 4,912 neighborhoods.

\begin{tabular}{|c|c|c|c|}
\hline & $\mathbf{n}$ & Unweighted Prevalence & Weighted Prevalence (SE) \\
\hline \multicolumn{4}{|c|}{ Trichomoniasis urine screen } \\
\hline Positive & 277 & 2.4 & $2.1(.21)$ \\
\hline Negative & 11,093 & 97.6 & $97.9(.21)$ \\
\hline \multicolumn{4}{|l|}{ Gender } \\
\hline Male & 5,318 & 46.7 & $50.4(.72)$ \\
\hline Female & 6,052 & 53.2 & $49.6(.72)$ \\
\hline \multicolumn{4}{|l|}{ Race and ethnicity } \\
\hline Hispanic & 1,859 & 16.4 & $11.6(1.7)$ \\
\hline Black & 2,286 & 20.1 & $15.0(2.0)$ \\
\hline Asian & 802 & 7.0 & $3.6(.74)$ \\
\hline American Indian & 100 & 0.9 & $0.7(.34)$ \\
\hline White (reference) & 6,323 & 55.6 & $69.0(2.9)$ \\
\hline \multicolumn{4}{|l|}{ Foreign born } \\
\hline Yes & 920 & 8.1 & $5.8(.84)$ \\
\hline No & 10,450 & 91.9 & $94.2(.84)$ \\
\hline \multicolumn{4}{|l|}{ Economic hardship } \\
\hline Yes & 824 & 7.3 & $7.0(.51)$ \\
\hline No & 10,546 & 92.7 & $93.0(.51)$ \\
\hline \multicolumn{4}{|l|}{ Employed } \\
\hline Yes & 7,995 & 70.3 & $70.6(.99)$ \\
\hline No & 3,375 & 29.7 & $29.4(.99)$ \\
\hline \multicolumn{4}{|l|}{ Enrolled in school } \\
\hline Yes & 4,312 & 37.9 & $36.8(1.5)$ \\
\hline No & 7,058 & 62.1 & $63.2(1.5)$ \\
\hline \multicolumn{4}{|l|}{ Married } \\
\hline Yes & 2,044 & 18.0 & $18.0(.99)$ \\
\hline No & 9,326 & 82.0 & $82.0(.99)$ \\
\hline \multicolumn{4}{|l|}{ Lives with parents } \\
\hline Yes & 4,507 & 39.6 & $38.9(1.3)$ \\
\hline No & 6,863 & 60.4 & $61.1(1.3)$ \\
\hline \multicolumn{4}{|c|}{ Heterosexual orientation } \\
\hline Yes & 10,174 & 89.5 & $89.7(.45)$ \\
\hline No & 1,196 & 10.5 & $10.3(.45)$ \\
\hline \multicolumn{4}{|c|}{ Antibiotic use past month } \\
\hline Yes & 1,535 & 13.5 & $13.8(.49)$ \\
\hline No & 9,835 & 86.5 & $86.2(.49)$ \\
\hline \multicolumn{4}{|l|}{ Age of first vaginal sex } \\
\hline $18-25$ years & 3,151 & 27.7 & $26.2(.97)$ \\
\hline
\end{tabular}




\begin{tabular}{|lccc|}
\hline & $\mathbf{n}$ & Unweighted Prevalence & Weighted Prevalence (SE) \\
\cline { 2 - 4 } 16-17 years & 3,524 & 31.0 & $31.3(.62)$ \\
10-15 years & 3,298 & 29.0 & $30.1(1.0)$ \\
Has not had vaginal sex & 1,397 & 12.3 & $12.4(.57)$ \\
Sex with IV drug user & & & \\
Yes & 74 & 0.7 & $.7(.12)$ \\
No & 11,296 & 99.3 & $99.3(.12)$ \\
Exchanged sex for money & & & $2.0(.22)$ \\
Yes & 253 & 2.2 & $98.0(.22)$ \\
No & 11,117 & 97.8 & $36.1(.95)$ \\
Drug use in past year & & & $63.9(.95)$ \\
Yes & 3,837 & 33.8 & \\
No & 7,533 & 66.2 & \\
\hline
\end{tabular}

\begin{tabular}{|c|c|c|c|}
\hline & & Unweighted Means (SD) & Weighted Means (SE) \\
\hline Age in years & 11,370 & $22.0(1.7)$ & $21.8(.12)$ \\
\hline Number of vaginal sex partners past year & 11,370 & $1.5(1.9)$ & $1.5(.03)$ \\
\hline Individual residential stability & 11,370 & $5.7(8.3)$ & $5.4(.21)$ \\
\hline Binge drinking episodes past year & 11,370 & $1.2(1.6)$ & $1.4(.04)$ \\
\hline
\end{tabular}


Table 2

Random effects logistic regression of the associations between neighborhood social disorganization and trichomoniasis among young adults aged 18-27 years, 2001-2002 National Survey of Adolescent Health (Add Health), $\mathrm{N}=11,370$ young adults across 4,912 neighborhoods.

\begin{tabular}{|c|c|c|c|}
\hline & $\begin{array}{l}\text { Model } 1 \\
\text { AOR }(95 \% \text { CI })\end{array}$ & $\begin{array}{l}\text { Model } 2 \\
\text { AOR }(95 \% \mathrm{CI})\end{array}$ & $\begin{array}{l}\text { Model } 3 \\
\text { AOR }(95 \% \text { CI })\end{array}$ \\
\hline \multicolumn{4}{|l|}{ Fixed Effects } \\
\hline \multicolumn{4}{|l|}{ Individual level } \\
\hline \multicolumn{4}{|l|}{ Sociodemographic characteristics } \\
\hline Age in years & $1.08(0.99,1.17)$ & $1.08(0.99,1.17)$ & $1.08(0.99,1.17)$ \\
\hline Male & $0.65(0.49,0.87)^{* *}$ & $0.65(0.49,0.87)^{* *}$ & $0.65(0.49,0.87)^{* *}$ \\
\hline \multicolumn{4}{|l|}{ Race and ethnicity } \\
\hline Hispanic & $1.72(1.07,2.79)^{*}$ & $1.75(1.08,2.83)^{*}$ & $1.75(1.07,2.84)^{*}$ \\
\hline Black & $3.45(2.41,4.94)^{* * *}$ & $3.47(2.43,4.96)^{* * *}$ & $3.54(2.47,5.08)^{* * * *}$ \\
\hline Asian & $1.84(0.96,3.55)$ & $1.89(0.98,3.65)$ & $1.93(0.99,3.75)$ \\
\hline American Indian & $1.53(0.33,7.16)$ & $1.53(0.33,7.16)$ & $1.52(0.32,7.14)$ \\
\hline White (ref) & 1.00 & 1.00 & 1.00 \\
\hline Foreign born & $0.97(0.54,1.74)$ & $0.98(0.55,1.75)$ & $0.97(0.54,1.75)$ \\
\hline Economic hardship & $1.72(1.23,2.40)^{* *}$ & $1.66(1.19,2.32)^{* *}$ & $1.65(1.18,2.31)^{* *}$ \\
\hline Employed & $0.66(0.52,0.84)^{* *}$ & $0.67(0.52,0.85)^{* *}$ & $0.67(0.53,0.86)^{* *}$ \\
\hline Enrolled in school & $0.65(0.48,0.88)^{* *}$ & $0.66(0.49,0.89)^{* *}$ & $0.67(0.50,0.91)^{*}$ \\
\hline Individual residential stability & $0.99(0.97,1.01)$ & $0.99(0.97,1.01)$ & $0.99(0.97,1.01)$ \\
\hline Married & $0.60(0.41,0.89)^{*}$ & $0.60(0.41,0.89)^{*}$ & $0.60(0.40,0.89)^{*}$ \\
\hline Lives with parents & $0.87(0.62,1.22)$ & $0.89(0.64,1.26)$ & $0.86(0.61,1.21)$ \\
\hline Heterosexual orientation & $1.07(0.72,1.60)$ & $1.06(0.71,1.59)$ & $1.06(0.71,1.59)$ \\
\hline Antibiotic use past month & $1.11(0.79,1.55)$ & $1.10(0.78,1.54)$ & $1.10(0.78,1.54)$ \\
\hline \multicolumn{4}{|l|}{ STI risk factors } \\
\hline \multicolumn{4}{|l|}{ Age of first vaginal sex } \\
\hline $18-25$ years & $1.24(0.74,2.11)$ & $1.24(0.73,2.10)$ & $1.23(0.73,2.08)$ \\
\hline $16-17$ years & $1.04(0.62,1.76)$ & $1.04(0.62,1.77)$ & $1.03(0.61,1.75)$ \\
\hline $10-15$ years & $1.46(0.87,2.46)$ & $1.45(0.86,2.44)$ & $1.43(0.85,2.40)$ \\
\hline Has not had vaginal sex (ref) & 1.00 & 1.00 & 1.00 \\
\hline Number vaginal sex partners & $0.99(0.94,1.05)$ & $0.99(0.94,1.05)$ & $0.99(0.94,1.05)$ \\
\hline Sex with IV drug user & $0.39(0.06,2.56)$ & $0.39(0.06,2.56)$ & $0.41(0.06,2.78)$ \\
\hline Exchanged sex for money & $1.34(0.74,2.41)$ & $1.32(0.73,2.39)$ & $1.33(0.74,2.40)$ \\
\hline Drug use in past year & $1.18(0.90,1.56)$ & $1.18(0.89,1.55)$ & $1.18(0.89,1.55)$ \\
\hline Binge drinking & $1.00(0.91,1.10)$ & $1.00(0.91,1.10)$ & $1.00(0.91,1.10)$ \\
\hline \multicolumn{4}{|l|}{ Neighborhood level } \\
\hline \multicolumn{4}{|l|}{ Neighborhood controls } \\
\hline Region & & & \\
\hline
\end{tabular}




\begin{tabular}{|c|c|c|c|}
\hline & $\begin{array}{l}\text { Model } 1 \\
\text { AOR }(95 \% \text { CI })\end{array}$ & $\begin{array}{l}\text { Model } 2 \\
\text { AOR }(95 \% \mathrm{CI})\end{array}$ & $\begin{array}{l}\text { Model } 3 \\
\text { AOR }(95 \% \text { CI })\end{array}$ \\
\hline West & $0.65(0.44,0.97)^{*}$ & $0.64(0.43,0.97)^{*}$ & $0.63(0.41,0.95)^{*}$ \\
\hline Midwest & $0.99(0.71,1.39)$ & $0.94(0.68,1.31)$ & $0.94(0.67,1.31)$ \\
\hline Northwest & $1.01(0.66,1.56)$ & $0.96(0.62,1.49)$ & $0.93(0.60,1.45)$ \\
\hline South (ref) & 1.00 & 1.00 & 1.00 \\
\hline Urbanicity & $0.96(0.79,1.16)$ & $0.98(0.87,1.11)$ & $1.02(0.89,1.18)$ \\
\hline \multicolumn{4}{|l|}{ Neighborhood disorganization } \\
\hline \multicolumn{4}{|l|}{ Racial/ethnic composition } \\
\hline Black concentration & $1.16(1.03,1.30)^{*}$ & $1.05(0.91,1.21)$ & $1.03(0.89,1.18)$ \\
\hline Immigrant concentration & $0.96(0.79,1.16)$ & $0.89(0.73,1.09)$ & $0.90(0.74,1.11)$ \\
\hline Concentrated poverty & & $1.19(1.02,1.38)^{*}$ & $1.25(1.07,1.46)^{* * *}$ \\
\hline Residential instability & & & $0.87(0.73,1.04)$ \\
\hline \multicolumn{4}{|l|}{ Random Effects } \\
\hline Intercept & $0.02(0.01,0.04)^{* * *}$ & $0.01(0.01,0.04)^{* * * *}$ & $0.02(0.01,0.04)^{* * *}$ \\
\hline
\end{tabular}

Unweighted analysis
${ }^{*} \mathrm{p}<0.05$
${ }^{* *} \mathrm{p}<0.01$
${ }^{* * *} \mathrm{p}<0.001$

